\title{
Breeding system and inbreeding depression in a translocated population of the endangered plant Dianthus morisianus (Caryophyllaceae)
}

\author{
Anna Nebot $^{\mathrm{a}, *}$, Donatella Cogoni ${ }^{\mathrm{a}}$, Giuseppe Fenu ${ }^{\mathrm{a}}$, Gianluigi Bacchetta ${ }^{\mathrm{a}, \mathrm{b}}$ \\ ${ }^{\text {a } C e n t r o ~ C o n s e r v a z i o n e ~ B i o d i v e r s i t a ̀ ~(C C B), ~ D i p a r t i m e n t o ~ d i ~ S c i e n z e ~ d e l l a ~ V i t a ~ e ~ d e l l ' A m b i e n t e, ~ U n i v e r s i t a ̀ ~ d e g l i ~ S t u d i ~ d i ~ C a g l i a r i, ~ V i a l e ~ S . ~ I g n a z i o ~ d a ~ L a c o n i ~ 13, ~ C a g l i a r i, ~}$ \\ 09123, Italy \\ ${ }^{\mathrm{b}}$ Hortus Botanicus Karalitanus (HBK), Università degli Studi di Cagliari, Viale Sant'Ignazio da Laconi, 9-11, Cagliari 09123, Italy
}

\section{A R T I C L E I N F O}

Edited by: Fei-Hai Yu

Keywords:

Translocation

Carnation

Reproductive success

Pollen limitation

Inbreeding depression

\begin{abstract}
A B S T R A C T
Know the breeding system of endemic plants is important to design conservation strategies. Translocations are actions to improve the survival prospects of the species, but nowadays there are only a few studies that analyse their success and make a comparison between translocation and the natural populations. Dianthus morisianus is a threatened narrow endemic plant species growing on sand dunes in SW Sardinia (Italy). The objective of this study was to assess the breeding system, the presence of inbreeding depression and pollen limitation, as well as the success of the plant translocation. All these results were compared with those from the single natural population. The breeding system was tested through five pollination treatments and the reproductive success was analysed by the fruit set, seed set, seed weight, germination and mortality rate. The translocated population behaved like the natural one on fruit and seed formation. Autonomous self-pollination was lower than the other treatments regarding fruit set and seed/ovule ratio in the two studied populations. The species is self-compatible and presents partial self-fertility. The selfing rate was higher in the translocated population and the inbreeding depression presented low values for the natural population, while the translocated population presented negative values. Neither of the populations suffered pollen limitation. The species did not present reproductive problems and it is pollinator dependent. Moreover, the translocated population demonstrated high success after five years, as an increase of the population area and new recruited plants was observed; the offspring were able to flower, fruiting and reproduce. This translocation success increases the survival prospects of the species.
\end{abstract}

\section{Introduction}

During the last few decades, biodiversity loss has been increasing rapidly mainly because of human activities (e.g. Díaz et al., 2006; Orsenigo et al., 2018). Populations of narrow endemic plants, which are often small and fragmented (e.g. Larrinaga et al., 2014), are often subject to a higher extinction risk (Cowling et al., 1996; Orsenigo et al., 2018; Cogoni et al., 2019) due to habitat degradation (e.g. Baillie et al., 2004), inbreeding depression (e.g. Keller and Waller, 2002) and/or pollinator decline (e.g. Aguilar et al., 2006), among others. Therefore, the establishment of new populations and the increase of the occupied area or the number of individuals of the existing populations can increase their survival capacity (Luijten et al., 2002; Cogoni et al., 2013). Recently, translocations have become well established as a tool to preserve threatened plant populations (Maschinski and Duquesnel, 2007; Godefroid et al., 2011; Cogoni et al., 2013; Fenu et al., 2019). Translocations are understood as the establishment of new populations to increase the survival prospects of a species by increasing population size and genetic diversity (Godefroid et al., 2011; Fenu et al., 2019). Translocation actions also entail subsequent studies aiming to verify their success and identify the possible factors that can cause the action to fail. To analyse the reproductive success of a translocated population it is important to compare the results with natural populations (e.g., Pavlik, 1996; Maschinski and Duquesnel, 2007; Colas et al., 2008; Monks et al., 2012; Guerrant, 2013; Menges et al., 2016). Although these studies can provide lots of useful information for future conservation actions, there are very few studies that compare them. The current definition of translocation success indicates that the population is able to persist and reproduce and it is characterized by a high survival rate and generates new individuals which are able to flower and produce fruits (e.g. Godefroid et al., 2011; Cogoni et al., 2013; Fenu et al., 2019). However, the population's persistence depends on several factors as the species' longevity, mating system, dispersal ability (Picó and Van Groenendael, 2007), the presence of inbreeding depression,

\footnotetext{
* Corresponding author.

E-mail addresses: annanebotescrigues@gmail.com (A. Nebot), d.cogoni@unica.it (D. Cogoni), gfenu@unica.it (G. Fenu), bacchet@unica.it (G. Bacchetta).
} 
outbreeding depression (Weisenberger et al., 2014), pollen limitation (Ashman et al., 2004), reproductive success (Schemske et al., 1994), interaction between pollinators and herbivory (Gargano et al., 2017), among others.

The breeding system is one of the numerous factors that influences the population persistence. The study of the breeding system can contribute to understanding biotic threats, determine to what extent it depends on pollinators and which is the survival capacity of the species in specific environments (Schemske et al., 1994; Fisogni et al., 2011). The reproductive success of pollinator dependent plant species can be also influenced by pollinator behaviour. Small plant populations are often less attractive to pollinators and this could cause pollen limitation (Ashman et al., 2004). Pollen limitation is often associated with low pollinator abundance (Gómez et al., 2010) and it can reduce the reproductive success in fragmented and small populations of pollinatordependent species (Aguilar et al., 2006), reduce population viability (Ashman et al., 2004; Fernández et al., 2012) and lead to selection in the plant mating system and floral traits (Ashman and Morgan, 2004). The consequences of pollen limitation (poor quality or quantity of pollen) have been widely investigated in the last years (e.g. Ashman et al., 2004; Lázaro and Traveset, 2006; Andersson et al., 2016; Gargano et al., 2017). The presence of inbreeding depression is another of the factors that influence the reproductive success. It is often a specific threat for narrow endemic species (Keller and Waller, 2002). The breeding system, the degree of fragmentation, the population size and the environmental conditions are some of the main factors that can influence the level of inbreeding depression (e.g. Angeloni et al., 2011). Furthermore, small population size is usually correlated with high values of inbreeding depression and it can also vary at the different stages of the life cycle, making it interesting to study both early and late stages of a particular species (Husband and Schemske, 1996).

Dianthus morisianus Vals. is a psammophilous threatened narrow endemic plant that grows only in one natural population on established sand dunes in Portixeddu (South-western Sardinia; Bacchetta et al., 2010). This species is considered as one of the most threatened on the island (Bacchetta et al., 2012) and it has been categorised as Critically Endangered on the IUCN Global Red List due to the strong degradation of its natural habitat (Fenu et al., 2017; Cogoni et al., 2019), the small population size (Fenu et al., 2013) and the limited seedling recruitment rate (Cogoni et al., 2012).

The aims of this study were to test the success of the first translocated population, improve the knowledge on the reproductive system of D. morisianus and its reproductive success to identify the potential biological factors that threaten this plant species. Previous studies analysed some characteristics of the breeding system of this species on ex situ cultivated plants (Nebot et al., 2016) and the flowering phenology (Nebot et al., 2018). However, the ability to autonomous selfpollination and the pollination vectors dependence have never been investigated. In particular, the specific aims were: 1) to deepen the knowledge of the success of the first translocation; 2) to gain information on the breeding system and related indexes in the two sites of study; 3 ) to evaluate the reproductive success of $D$. morisianus.

\section{Material and methods}

\subsection{Plant species}

Dianthus morisianus Vals. (Caryophyllaceae) is a perennial rizhomatous plant characterised by numerous woody stocks, erect stems and by a basal rosette with thin and linear leaves. The stems bear terminal multi-flowered heads; the calyx is characterised by lanceolate teeth and the colour of the corolla is normally pink (Bacchetta et al., 2010). D. morisianus is a gynomonoecious plant that presents hermaphroditic and, in low frequency, female flowers. It is a self-compatible species, with mixed mating system (Nebot et al., 2016). The flowering season is from early May to late June, and ripe fruits can be found during June-July
(Nebot et al., 2018). Seedling emergence represents the most critical stage for the long-term persistence of $D$. morisianus, while the lack of a persistent soil seed bank represents a hazard to the persistence of the natural population (Cogoni et al., 2012).

In 2010 was conducted a first translocation of this species. It consisted on 113 transplants in a fenced site ca. $150 \mathrm{~m}$ away from the natural population (Cogoni et al., 2013). In 2012 was conducted a second translocation with 25 plants placed in an unprotected area, $1.3 \mathrm{~km}$ away from the natural population and $1.05 \mathrm{~km}$ from the first translocation site (Cogoni et al., 2013; Fenu et al., 2015). In both cases, the transplants come from seeds randomly collected in the natural population on 2008 and 2009 (both years these were sampled fruits from at least 50 mature plants). Seeds from each collection were incubated at the optimum germination conditions for the species and subsequently the seedlings were placed in pots with sand from the natural population habitat (Cogoni et al., 2013). The plants were cultivated at the Botanic Garden of the Cagliari University without horticultural treatments before the translocation (Cogoni et al., 2013). However, plants from the second translocation were not considered in this study because they suffered high damage by herbivores and human disturbance (Fenu et al., 2016). In this work studied plants were divided into: natural plants (plants from the natural population), offspring (offspring from planted plants in the translocation site) and translocated plants (those planted).

\subsection{Breeding system}

The reproductive experiments were conducted on 50 offspring of translocated plants (five years after the translocation) and 60 plants in the natural population. Plants were randomly selected and were separated more than five metres apart from one another. The breeding system was analysed by performing five different pollination treatments following Dafni et al. (2005) (Table 1 Appendix A). Flowers were bagged with a fine mesh bag prior to anthesis to prevent pollination. To test the geitonogamy and xenogamy treatments, bagged flowers were manually emasculated and hand-pollinated when stigmas were receptive. To test the geitonogamy ability, flowers were pollinated with pollen coming from a flower of the same plant; while those used to test the within-population xenogamy were pollinated with pollen coming from a plant located in the same population (more than five metres away from the pollinated plant to avoid a parental relationship). To analyse the ability of autonomous self-pollination, un-manipulated flowers were bagged till fructification. The presence of pollen limitation in the population was analysed by supplemental pollination experiments, which consisted of carrying out supplemental manual pollination (with pollen of a plant growing far from the studied plant) on flowers which were openly pollinated. Finally, the control treatment allowed us to compare the different pollination treatments with the reproductive success in nature. All treated capsules were collected when ripe and taken to the laboratory. The reproductive success of each treatment was evaluated by fruit set (ratio of fruits to treated flowers), seed set (ratio of seeds to the average number of ovules), and seed weight. The results were then compared between the plants of the two populations. Additionally, the Self-Fertility Index (SFI), and the SelfCompatible Index (SCI) according to Lloyd and Schoen (1992) were calculated. The SFI indicates the ability of the plants to produce seeds in the absence of pollinators; the following formula was used: SFI = seed/ ovule of autonomous self-pollination / seed/ovule of the xenogamy treatment. SCI shows the level of self-compatibility of the species and it was obtained through the formula: seed/ovule of geitonogamy / seed/ ovule of xenogamy. Moreover, the selfing rate (S) was calculated using the formula proposed by Charlesworth and Charlesworth (1987): S = (xenogamy-control) / (xenogamy-geitonogamy). In this study, the geitonogamy values were used instead of autonomous self-pollination following Aizen and Basilio (1995). Values between 0 and 0.5 indicate null or partial self-fertility or self-incompatibility, while values until 1 


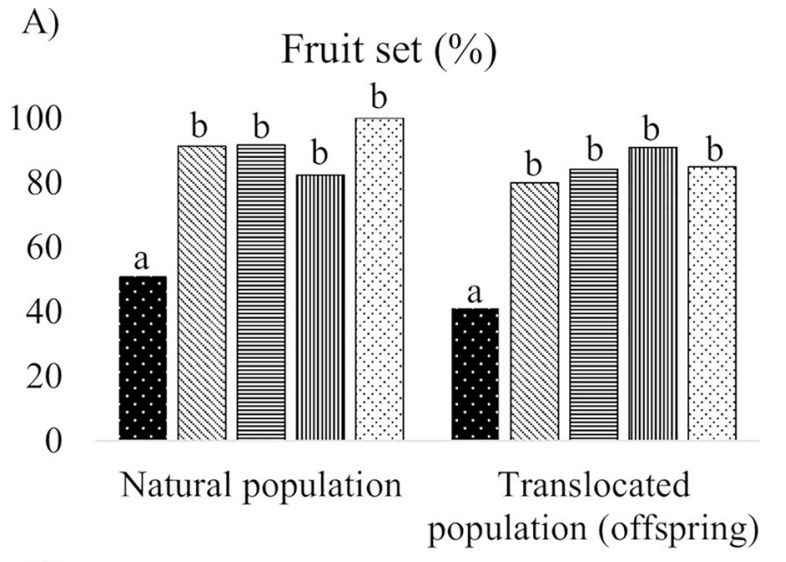

C)

E)

100

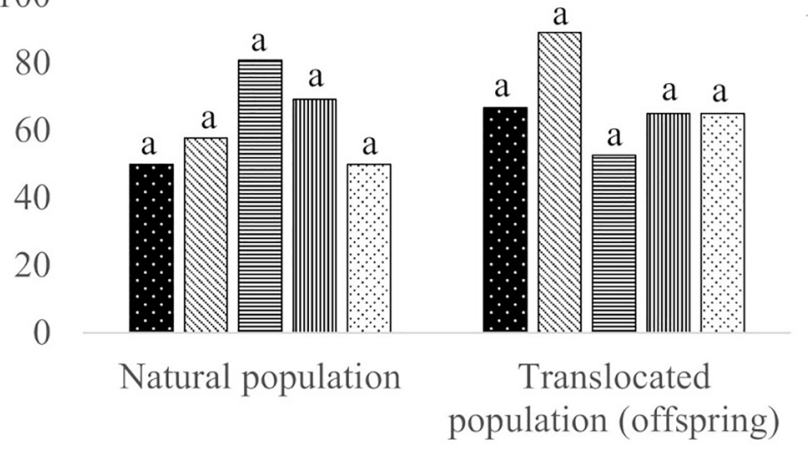

B)

\section{Aborted seeds $\left(\mathrm{n}^{\circ}\right)$}

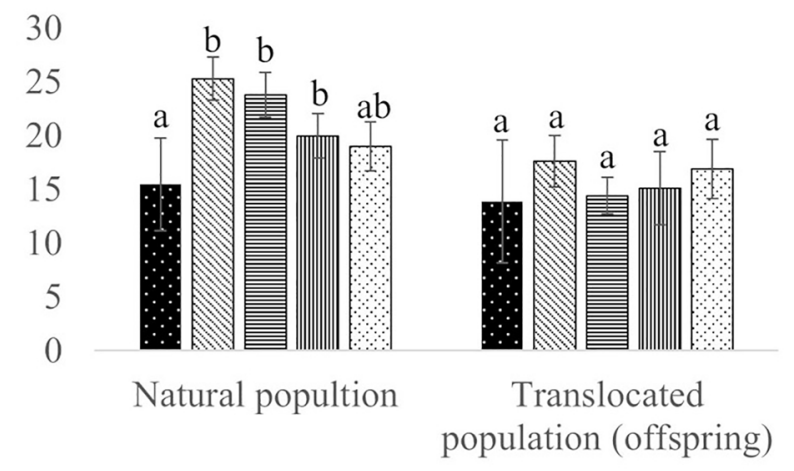

D)

Seed weight (mg)

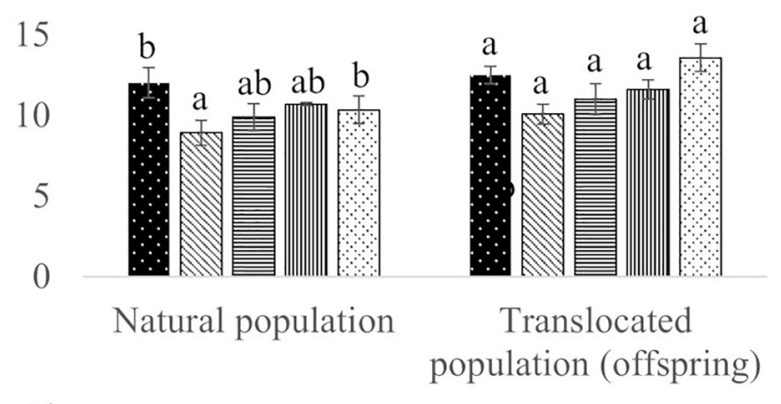

F)

Mortality rate (\%)

80

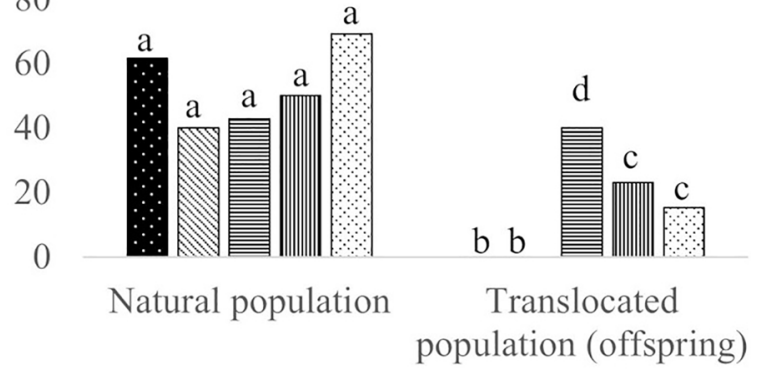

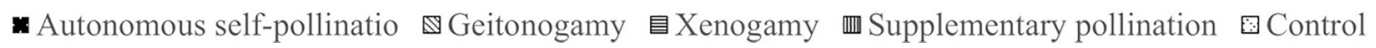

Fig. 1. Reproductive success (mean \pm SD) of the studied plants in the natural and translocated (offspring) populations calculated in field conditions during 2015. Different letters indicate significant differences among parameters at $P<0.05$.

indicate preference of self-fertile or self-compatible. The Pollen Limitation index (PL) was calculated following Tamura and Kudo (2000) through the formula: PL $=1$ - (control/supplementary). Values near 0 indicate absence of pollen limitation, while values near 1 indicate high pollen limitation.

The inbreeding depression $(\delta)$ was calculated following the formula proposed by Charlesworth and Charlesworth (1987): $\delta=1-\left(W_{s} / W_{o}\right)$, where $W_{s}$ is the mean success of the geitonogamy treatment and $W_{o}$ the mean success of the xenogamy treatment. The inbreeding depression was studied on five parameters of success (fruit set, seed set, seed weight, germination rate in field, and time to germinate). The cumulative level of inbreeding depression of all the analysed parameters was assessed following the formula of Husband and Schemske (1996):

$\delta_{\mathrm{c}}=1-\left[\left(W_{s a} / W_{o a}\right) \times\left(W_{s b} / W_{o b}\right) \times\left(W_{s c} / W_{o c}\right) \times\left(W_{s d} / W_{o d}\right) \times\left(W_{s e} /\right.\right.$ $\left.\left.W_{o e}\right) \times\left(W_{s f} / W_{o f}\right)\right]$
Values of inbreeding depression range from -1 to 1 , where 0 indicates the absence of inbreeding depression, positive values that the outcrossed offspring outperform the selfed offspring (inbreeding depression) and negative ones outbreeding depression (Charlesworth and Charlesworth, 1987).

\subsection{Plant traits}

To analyse the plant traits, 146 and 182 plants were randomly selected from the natural and translocated sites respectively. Plants were divided into natural (146), translocated (82 plants) and offspring of the translocated plants (100 plants). The plant traits analysed on each individual were: the number of stems, the height of the taller stem $(\mathrm{cm}$; hereafter "height"), the number of buds per stem and plant (buds) and the distance of the nearest plant ( $\mathrm{dm}$; "distance"). These were measured and counted prior to flowering. After the pollination event, the total 
formed fruits and the number of fruits affected by herbivory and parasitism were counted. For each plant two fruits were selected and the number of ovules and seeds were counted and weighted (mean weight of 10 seeds).

\subsection{Germination experiments in the field}

Seeds obtained in the breeding system experiment were sown in the field to analyse monthly the germination and mortality rate of the seeds. For each pollination treatment, three replicates of 10 seeds were sown by placing them in biodegradable peat pots. Each seed was sown at a depth of c. $0.5-1 \mathrm{~cm}$, as detailed in Cogoni et al. (2012). This experiment started at the beginning of September 2015 and was monthly monitored until April 2016. On each census the germination and mortality rate of the seedlings were recorded. The results were compared among pollination treatments and among populations (natural vs. translocated) to verify if there were any differences.

\subsection{Statistical analyses}

The effect of the pollination treatments on the female reproductive success of $D$. morisianus in both natural and translocated populations was tested with Generalized Linear Models (GLMs). In order to evaluate the success of the translocation, GLMs were also used to compare vegetative and reproductive traits among the natural population, the translocated plants and the offspring of the translocated plants. The different parameters characterizing the reproductive success and the vegetative and reproductive traits were analysed as response variables, while the pollination treatment and population were considered factors. The Gaussian distribution was assumed with identity link when the data were normally distributed, a Poisson distribution with a log function when the data were not normal, and a binomial distribution with a logit link function for proportions. Different models were fitted for each response variable and the model with the lowest Akaike Information Criterion (AIC; Crawley, 2007) was selected. The presence of significant differences among the different response variables were checked through the function $g \operatorname{lht}()$ of the package multcomp version 1.4-6 (Hothorn et al., 2008) using multiple comparisons of means with Tukey contrasts. All analyses were performed with R version 3.6.1 (R Core Team, 2019).

\section{Results}

\subsection{Breeding system}

All pollination treatments produced fruits and seeds, but the reproductive success varied among treatments. Autonomous self-pollination produced significantly less fruit set and seed/ovule ratio $(P<0.05)$ comparing to the other treatments (Fig. 1A, C). There were no significant differences among plants from the two populations neither on fruit set nor on seed/ovule ratio $(P>0.05$; Table 1$)$. The number of aborted seeds only presented significant differences on plants belonging to the natural population $(P<0.05$; Table 1$)$. The autonomous self-pollination presented significantly fewer aborted seeds than the other treatments (Fig. 1B). The control treatment produced a mean of $33.18 \pm 13.87$ seeds per fruit on plants from the translocated population, while plants from the natural population produced a mean of $36.44 \pm 17.29$ seeds. The weight of the seeds was only influenced by the interaction of the population and treatments at the natural population $(P<0.05$; Table 1$)$. The plants from the translocated population produced heavier seeds than those from natural population (Fig. 1D).

Our results showed that the species is self-compatible (SCI $=0.94$ in both populations) and self-fertile (SFI $=0.18$ on the translocated population and 0.21 in the natural population). The selfing rate values were 0.66 and -0.13 for the translocated and natural population,
Table 1

Statistical results of the GLMs carried out to analyse the effects of the pollination treatments and populations on the studied parameters. The significant differences are indicated in bold.

\begin{tabular}{llll}
\hline Measure & Factor & d.f. & $P>$ chi-square \\
\hline \multirow{2}{*}{ Fruit set } & Treatment & 4 & $<\mathbf{0 . 0 1 0}$ \\
& Population & 1 & 0.074 \\
Seed/ovule & Treatment*population & 4 & 0.111 \\
& Treatment & 4 & $<\mathbf{0 . 0 0 1}$ \\
Aborted seed & Population & 1 & 0.502 \\
& Treatment*population & 4 & 0.780 \\
Seed weight & Treatment & 4 & 0.179 \\
& Population & 1 & $\mathbf{0 . 0 4 6}$ \\
& Treatment*population & 4 & 0.421 \\
Germination rate & Treatment & 4 & 0.172 \\
& Population & 1 & 0.578 \\
& Treatment*population & 4 & $\mathbf{0 . 0 2 7}$ \\
Mortality rate & Treatment & 4 & 0.226 \\
& Population & 1 & 0.573 \\
& Treatment*population & & 0.122 \\
& Treatment & 4 & 0.1727 \\
& Population & 1 & $<\mathbf{0 . 0 1 0}$ \\
& Treatment*population & 4 & $\mathbf{0 . 0 4 4}$
\end{tabular}

respectively. Hand pollinations on openly pollinated flowers did not significantly increase the reproductive success; the PL index supported this result with a value of 0.22 and 0.24 in the translocated and natural populations, respectively.

\subsection{Germination tests}

There were no significant differences in the germination rate among seeds belonging to the different treatments in the plants of the two populations $(P>0.05$; Table 1 ; Fig. $1 \mathrm{E})$. November was the month with the highest germination rate $(55 \%)$ and December the month with the highest mortality rate $(56.25 \%)$. The seedlings from the translocated population presented significantly lower mortality rate than those from the natural population $(P<0.05$; Table 1 ; Fig. 1 F). The mortality rate was also affected by the interaccion among the treatments and population $(P<0.05$; Table 1$)$, but not by the pollination treatments $(P>0.05 ;$ Table 1$)$.

\subsection{Inbreeding depression}

Plants from the translocated population presented negative inbreeding depression on seed weight, germination rate and time to germinate, therefore indicating the presence of outbreeding depression (Table 2). Instead, plants from the natural population only presented inbreeding depression on germination rate (Table 2). The cumulative values of inbreeding depression varied between populations, see Table 2 .

Table 2

Coefficients of inbreeding depression ( $\delta$ ) in different traits of Dianthus morisianus obtained in the natural and offspring from translocated plants.

\begin{tabular}{lll}
\hline Plant traits & $\delta$ & \\
\cline { 2 - 3 } & $\begin{array}{l}\text { Natural } \\
\text { population }\end{array}$ & $\begin{array}{l}\text { Translocated population } \\
\text { (offspring) }\end{array}$ \\
\hline Fruit set (\%) & 0.01 & 0.05 \\
Seed set (\%) & 0.11 & 0.06 \\
Seed weight 10 seeds (mg) & 0.12 & -0.25 \\
Germination rate field (\%) & 0.29 & -0.66 \\
Time to germinate & -0.06 & -0.23 \\
Cummulative inbreeding depression & 0.35 & -0.66 \\
\hline
\end{tabular}


Table 3

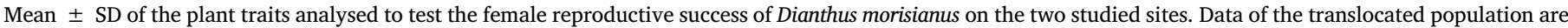

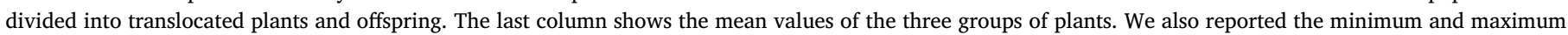
values of each parameter. Different letters indicate significant differences at $\mathrm{P}<0.05$.

\begin{tabular}{|c|c|c|c|c|c|}
\hline & \multirow{2}{*}{$\begin{array}{l}\text { Plants from natural } \\
\text { population }\end{array}$} & \multicolumn{3}{|c|}{ Plants from translocated population } & \multirow{2}{*}{$\begin{array}{l}\text { Mean values of all studied } \\
\text { plants }\end{array}$} \\
\hline & & $\begin{array}{l}\text { Translocated plants } \\
(\mathrm{n}=82)\end{array}$ & Offspring $(\mathrm{n}=100)$ & $\begin{array}{l}\text { Mean translocated } \\
\text { population }\end{array}$ & \\
\hline $\mathrm{N}^{\mathrm{o}}$ of stems & $\begin{array}{l}5.1 \pm 4.58^{\mathrm{a}} \\
(1-36)\end{array}$ & $\begin{array}{l}15.73 \pm 0.88^{b} \\
(1-66)\end{array}$ & $\begin{array}{l}6.02 \pm 4.44^{c} \\
(1-20)\end{array}$ & $\begin{array}{l}10.20 \pm 10.56^{\mathrm{d}} \\
(1-66)\end{array}$ & $\begin{array}{l}8.45 \pm 9.28 \\
(1-66)\end{array}$ \\
\hline № buds/stems & $\begin{array}{l}2.13 \pm 1.02^{\mathrm{a}} \\
(0.8-8)\end{array}$ & $\begin{array}{l}2.48 \pm 0.88^{b} \\
(1-5.64)\end{array}$ & $\begin{array}{l}2.93 \pm 1.07^{c} \\
(1-6)\end{array}$ & $\begin{array}{l}2.74 \pm 1.02^{\mathrm{d}} \\
(0.8-8)\end{array}$ & $\begin{array}{l}2.53 \pm 1.05 \\
(0.8-8)\end{array}$ \\
\hline $\mathrm{N}^{\circ}$ of buds & $\begin{array}{l}10.19 \pm 9.09^{\mathrm{a}} \\
(1-72)\end{array}$ & $\begin{array}{l}39.96 \pm 10.03^{b} \\
(3-198)\end{array}$ & $\begin{array}{l}16.22 \pm 13.20^{c} \\
(2-74)\end{array}$ & $\begin{array}{l}26.41 \pm 29.33^{\mathrm{d}} \\
(1-198)\end{array}$ & $\begin{array}{l}20.63 \pm 25.37 \\
(1-198)\end{array}$ \\
\hline Plant height $(\mathrm{cm})$ & $\begin{array}{l}36.25 \pm 10.34^{\mathrm{a}} \\
(5-68)\end{array}$ & $\begin{array}{l}45.48 \pm 0.31^{\mathrm{b}} \\
(21-67)\end{array}$ & $\begin{array}{l}41.72 \pm 8.87^{c} \\
(27-71)\end{array}$ & $\begin{array}{l}43.31 \pm 9.53^{d} \\
(5-71)\end{array}$ & $\begin{array}{l}40.92 \pm 10.42 \\
(5-71)\end{array}$ \\
\hline Distance $(\mathrm{cm})$ & $\begin{array}{l}77.85 \pm 90.63^{\mathrm{a}} \\
(8-520)\end{array}$ & $\begin{array}{l}65.50 \pm 34.40^{b} \\
(8-120)\end{array}$ & $\begin{array}{l}95.70 \pm 133.00^{\mathrm{a}} \\
(13-770)\end{array}$ & $\begin{array}{l}67.98 \pm 84.91^{c} \\
(8-770)\end{array}$ & $\begin{array}{l}73.89 \pm 91.62 \\
(8-770)\end{array}$ \\
\hline $\mathrm{N}^{\circ}$ of fruits & - & $\begin{array}{l}33.03 \pm 35.21^{\mathrm{a}} \\
(1-157)\end{array}$ & $\begin{array}{l}13.88 \pm 13.79^{b} \\
(1-70)\end{array}$ & $\begin{array}{l}22.52 \pm 27.21 \\
(1-157)\end{array}$ & - \\
\hline Fruit set (\%) & - & $\begin{array}{l}73.80 \pm 27.39^{\mathrm{a}} \\
(10.71-100)\end{array}$ & $\begin{array}{l}74.33 \pm 28.14^{\mathrm{a}} \\
(5.26-100)\end{array}$ & $\begin{array}{l}74.09 \pm 27.71 \\
(5.26-100)\end{array}$ & - \\
\hline Mean weight of 10 seeds (mg) & - & $\begin{array}{l}12.60 \pm 8.40^{\mathrm{a}} \\
(6.96-46.04)\end{array}$ & $\begin{array}{l}12.70 \pm 5.90^{\mathrm{a}} \\
(6.84-48.76)\end{array}$ & $\begin{array}{l}12.70 \pm 7.20 \\
(6.84-48.76)\end{array}$ & - \\
\hline № of seeds/fruit & - & $\begin{array}{l}34.73 \pm 15.61^{\mathrm{a}} \\
(5-76)\end{array}$ & $\begin{array}{l}33.38 \pm 13.87^{\mathrm{a}} \\
(8-69)\end{array}$ & $\begin{array}{l}33.38 \pm 13.87 \\
(5-76)\end{array}$ & - \\
\hline Seed/ovule & - & $\begin{array}{l}44.79 \pm 23.774^{\mathrm{a}} \\
(6.47-98.3)\end{array}$ & $\begin{array}{l}43.88 \pm 20.45^{\mathrm{a}} \\
(10.35-89.24)\end{array}$ & $\begin{array}{l}44.28 \pm 22.02 \\
(6.47-98.3)\end{array}$ & - \\
\hline Hervibory (\% plants) & 83.31 & 9.23 & 26.19 & 18.79 & 59.54 \\
\hline Parasitism (\% fruits) & - & 25.76 & 24.07 & - & - \\
\hline Self-pollination index (SFI) & 0.21 & - & 0.18 & - & - \\
\hline Self-compatible index (SCI) & 0.94 & - & 0.94 & - & - \\
\hline Selfing rate (S) & -0.13 & - & 0.66 & - & - \\
\hline Pollen limitation (PL) & 0.24 & - & 0.22 & - & - \\
\hline
\end{tabular}

\subsection{Plant traits}

The number of stems, buds, buds per stems and height of the stems varied significantly among the three groups of plants (Table 3). Plants from natural population presented lower values of those of the translocated population. The distance between plants was longer in the translocated population (with a maximum of $770 \mathrm{~cm}$ away) but there were not significant differences between populations. The two populations were affected by herbivory. The parasitism was only tested on the translocated population due to the high herbivory suffered on the natural population (Table 3 ).

\section{Discussion}

Our study confirmed that $D$. morisianus is a self-compatible plant with a mixed mating system, as previously observed on ex situ cultivated plants (Nebot et al., 2016). In addition, the result corroborates the utility of breeding system studies on ex situ plants of narrow endemic plant species. The significant differences in fruit set and seed/ ovule ratio between the geitonogamy treatment and the autonomous self-pollination could be due to the proterandry of the species or to the age of the pollen. These results were not caused by genetic incompatibility, as demonstrated by the geitonogamy treatment, but could be due to the low quantity and quality of pollen available when styles are receptive, as reported for Silene acutifolia (Buide and Guitián, 2002). In $D$. morisianus, pollen was exposed for three to five days until the styles reached their maturity (Nebot et al., 2016). In this case, dichogamy may reduce the capacity of self-pollination but cannot avoid it.

The SFI values indicated that our species is characterized by partial self-fertility. Self-fertility is an advantageous characteristic to maintain the reproductive assurance in the absence or reduction of pollinators (Kalisz and Vogler, 2003). In the plants from translocated population higher selfing values were obtained than in the plants from the natural one; however, we have no consistent data to clarify this aspect and, then, a deeper study should be conducted to better understand these results. One hypothesis, which should be tested in the future, should be that this population is still "young" and there are few individuals, or by the high floral display per plant which cause pollinators to stay on the same plant instead of moving around the population as reported by Culley et al. (1999). The control flowers of plants from the natural population produced more seeds than flowers subjected to autonomous self-pollination treatment, and this could indicate that the seed production is highly dependent on pollinators. This was supported by the low SFI values, that indicated the need of pollinators to obtain high reproductive success.

The results of the supplemental and control treatments highlighted that this species is not affected by pollen limitation the year of study. This result is in accordance with previous studies (e.g. Fenster and Martén-Rodríguez (2007), which indicated that many self-compatible species have an ability to autonomously self-pollinate and thus are usually characterized by low levels of pollen limitation (Alonso et al., 2010). Conversely, these results show the opposite to some reviews which indicate that pollen limitation is widespread in plants (e.g. Larson and Barrett, 2000; Ashman et al., 2004).

The significant differences on seed weight observed in autonomous self-pollination compared to the geitonogamy treatment may be triggered by the different resource allocation (Guo et al., 2010). The number of seeds did not affect their weight on the offspring, an opposite pattern to that observed in the plants from the natural population. These differences could indicate that there are not limiting resources in the translocated area; in fact, the translocation is located in an open sandy area and consists of few plants, while the natural population grows in a vegetated area.

Plants from translocated population were characterized by outbreeding depression at seed weight, germination rate and time to germinate. This situation is fairly common in translocated populations originated by a mix of seeds collected from different populations (Dudash and Fenster, 2000; Bouzat, 2010). However, in our case, the 
translocated plants came from the only one existing population and, as mentioned before, these results should be taken cautiously until a deepen study to understand the procedence of the inbreeding and outbreeding depression. The outbreeding depression, just like the inbreeding depression, can be stronger in later stages (Edmands and Timmerman, 2003), which is in accordance with our results. Contrary to plants from the translocated population, the natural plants of $D$. morisianus showed low values of inbreeding depression in the natural population ( 0.29 the highest value for the germination rate), the same level of inbreeding depression was observed in other narrowly distributed congeneric species (e.g. D. guliae; Gargano et al., 2009). The results of the plants from natural population are in accordance with Husband and Schemske (1996), who indicated that inbreeding depression can be also found at the germination stage, and the current low values could be due to the purge of lethal and deleterious alleles. In addition, they support the results obtained in the ex situ experiment where $D$. morisianus presented inbreeding depression in seed germination speed (T50; Nebot et al., 2016). The results of inbreeding depression indicate that $D$. morisianus could be protected by the inbreeding depression generated by selfing. In this study the inbreeding depression was observed only in the germination rate and the cumulative inbreeding depression was higher than that obtained on ex situ cultivated plants (Nebot et al., 2016). This result is in accordance with Goodwillie et al. (2005) which indicated that field conditions increase the level of inbreeding depression.

Plants from translocated population have a reproductive output similar to the natural one. It consists of numerous offspring (more than $50 \%$ were tested; Fenu et al., 2016) that are able to flower and produce fruits as previously observed (Nebot et al., 2018). Plants are also bigger than the natural ones. Fenu et al. (2016) indicated an increase of the number of stems in the translocated population year after year and in the fifth year of the translocation (2016) this pattern continued (A. Nebot, personal communication). The higher values of offsprings could suggest that there is a higher availability of resources (Ollerton and Lack, 1998) in the translocation area than in the natural population, where the level of competition among species is higher.

In Nebot et al. (2018) high floral display and flowering synchrony in the translocation were observed. These flowering characteristics may highly contribute to attract pollinators (Grindeland et al., 2005) and therefore facilitating the reproductive success of $D$. morisianus. Other factors demonstrate success in the translocation, as there was an increase of the area occupied by the population and was observed dispersal ability. There were observed offspring more than seven metres away from the nearest plant. The great production of seeds in the translocation area is advantageous considering the low establishment of seedlings observed in the natural population (Cogoni et al., 2012).

The high levels of herbivory observed in the natural population indicated that this could be an important threat for the species due to it also affects the traits to attract pollinators (Gargano et al., 2017). In the translocated population the herbivory was lower because of the fence, but did not eliminated it.

\section{Conclusions}

Dianthus morisianus is a self-compatible pollinator-dependent species with a mixed-mating system, and it has no pollen limitation problems during the year of study. The natural population presented low values of inbreeding depression, meanwhile plants from the translocation presented some outbreeding depression on seed weight and germination parameters. In future studies it will be necessary to study the inbreeding depression on translocated and offspring plants of different generations to better understand the procedence and the effect that it has on the species. The translocation of $D$. morisianus presented high success after five years: as there was high survival rate of transplants, was observed establishment of new plants which were able to reproduce, persisted over the years, presented vegetative growth and population was able to disperse the seeds. As indicated by Pavlik (1996), this is a key to define a successful translocation. The translocation rises the survival prospects of the species increasing the occupied area. All these results are encouraging for the survival of the species and, together with demographic information (e.g. Cogoni et al., 2019), can help us plan species-specific conservation measures. In future studies plant-animal interactions should be studied both in the natural and translocated plants to analyse how pollinators, herbivory and parasitism influence the reproductive success of $D$. morisianus, and the survival capacity of the species. As observed by Dalrymple et al. (2012), monitoring should take more than 10 years to really know the longterm persistence of the reintroduced population. High success during the first years does not imply success in the long-term. This study was conducted after five years of the reintroduction action, then, a future study about the translocation success should be done to analyse the long-term persistence of the population.

\section{Declaration of Competing Interest}

The authors declare that they have no known competing financial interests or personal relationships that could have appeared to influence the work reported in this paper.

\section{Acknowlegments}

This research was supported by Università degli Studi di Cagliari. The authors thank the FoReSTAS Agency for the field work logistic support and Alberto Górriz Doñate for his assistance in field experiments.

\section{Appendix A. Supplementary data}

Supplementary data associated with this article can be found, in the online version, at https://doi.org/10.1016/j.flora.2019.151488.

\section{References}

Aguilar, R., Ashworth, L., Galetto, L., Aizen, M.A., 2006. Plant reproductive susceptibility to habitat fragmentation: review and synthesis through a meta-analysis. Ecol. Lett. 9, 968-980. https://doi.org/10.1111/j.1461-0248.2006.00927.x.

Aizen, M.A., Basilio, A., 1995. Within and among flower sex-phase distribution in Alstroemeria aurea (Alstroemeriaceae). Can. J. Bot. 73, 1986-1994. https://doi.org/ 10.1139/b95-213.

Alonso, C., Vamosi, J.C., Knight, T.M., Steets, J.A., Ashman, T.L., 2010. Is reproduction of endemic plant species particularly pollen limited in biodiversity hotspots? Oikos 119 , 1192-1200. https://doi.org/10.1111/j.1600-0706.2009.18026.x.

Andersson, P., Ehrlén, J., Hambäck, P.A., 2016. Plant patch structure influences plant fitness via antagonistic and mutualistic interactions but in different directions. Oecologia 180, 1175-1182. https://doi.org/10.1007/s00442-015-3532-y.

Angeloni, F., Ouborg, N.J., Leimu, R., 2011. Meta-analysis on the association of population size and life history with inbreeding depression in plants. Biol. Conserv. 144 35-43. https://doi.org/10.1016/j.biocon.2010.08.016.

Ashman, T.-L., Knight, T.M., Steets, J.A., Amarasekare, P., Burd, M., Campbell, D.R., Dudash, M.R., Johnston, M.O., Mazer, S.J., Mitchell, R.J., Morgan, M.T., Wilson, W.G., 2004. Pollen limitation of plant reproduction: ecological and evolutionary causes and consequences. Ecology 85, 2408-2421. https://doi.org/10.1890/038024.

Ashman, T.L., Morgan, M.T., 2004. Explaining phenotypic selection on plant attractive characters: male function, gender balance or ecological context? Proc. R. Soc. B Biol. Sci. 271, 553-559. https://doi.org/10.1098/rspb.2003.2642.

Bacchetta, G., Brullo, S., Casti, M., Pietro Giusso del Galdo, G., 2010. Taxonomic revision of the Dianthus sylvestris group (Caryophyllaceae) in central-southern Italy, Sicily and Sardinia. Nord. J. Bot. 28, 137-173. https://doi.org/10.1111/j.1756-1051.2009. 00459.x.

Bacchetta, G., Fenu, G., Mattana, E., 2012. A checklist of the exclusive vascular flora of Sardinia with priority rankings for conservation. An. del Jardín Botánico Madrid 69, 81-89. https://doi.org/10.3989/ajbm.2289.

Baillie, Jonathan, Hilton-Taylor, Craig, Stuart, S.N., 2004. 2004 IUCN Red List of Threatened Species : a Global Species Assessment. UICN, Gland, Switzerland and Cambridge.

Bouzat, J.L., 2010. Conservation genetics of population bottlenecks: the role of chance, selection, and history. Conserv. Genet. 11, 463-478. https://doi.org/10.1007/ s10592-010-0049-0.

Buide, M.L., Guitián, J., 2002. Breeding system in the dichogamous hermaphrodite Silene 
acutifolia (Caryophyllaceae). Ann. Bot. 90, 691-699. https://doi.org/10.1093/aob/ mcf251.

Charlesworth, D., Charlesworth, B., 1987. Inbreeding depression and its evolutionary consequences. Annu. Rev. Ecol. Syst. 18, 237-268. https://doi.org/10.1146/annurev. es.18.110187.001321.

Cogoni, D., Fenu, G., Concas, E., Bacchetta, G., 2013. The effectiveness of plant conservation measures: the Dianthus morisianus reintroduction. Oryx 47, 203-206. https://doi.org/10.1017/S003060531200169X.

Cogoni, D., Mattana, E., Fenu, G., Bacchetta, G., 2012. From seed to seedling: a critical transitional stage for the Mediterranean psammophilous species Dianthus morisianus (Caryophyllaceae). Plant Biosyst. - An Int. J. Deal. with all Asp. Plant Biol. 146, 910-917. https://doi.org/10.1080/11263504.2011.647106.

Cogoni, D., Sulis, E., Bacchetta, G., Fenu, G., 2019. The unpredictable fate of the single population of a threatened endemic Mediterranean plant. Biodivers. Conserv. 28, 1799-1813. https://doi.org/10.1007/s10531-019-01757-0.

Colas, B., Kirchner, F., Riba, M., Olivieri, I., Mignot, A., Imbert, E., Beltrame, C., Carbonell, D., Fréville, H., 2008. Restoration demography: a 10-year demographic comparison between introduced and natural populations of endemic Centaurea cor ymbosa (Asteraceae). J. Appl. Ecol. 45, 1468-1476. https://doi.org/10.1111/j.13652664.2008.01536.x.

Cowling, R.M., Rundel, P.W., Lamont, B.B., Kalin Arroyo, M., Arianoutsou, M., 1996 Plant diversity in mediterranean-climate regions. Trends Ecol. Evol. (Amst.) 11, 362-366. https://doi.org/10.1016/0169-5347(96)10044-6.

Culley, T.M., Weller, S.G., Sakai, A.K., Rankin, A.E., 1999. Inbreeding depression and selfing rates in a self-compatible, hermaphroditic species, Schiedea membranacea (Caryophyllaceae). Am. J. Bot. 86, 980-987. https://doi.org/10.2307/2656615.

Dafni, A., Kevan, P.G., Husband, B., 2005. Practical Pollination Biology. Enviroquest Ltd., Cambridge, Canada.

Dalrymple, S.E., Banks, E., Stewart, G.B., Pullin, A.S., 2012. A meta-analysis of threatened plant reintroductions from across the globe. In: Maschinski, J., Haskins, K.E., Raven, P.H. (Eds.), Plant Reintroduction in a Changing Climate. The Science and Practice of Ecological Restoration. Island Press, Washington, DC.

Díaz, S., Fargione, J., Chapin, F.S., Tilman, D., 2006. Biodiversity loss threatens human well-being. PLoS Biol. 4, e277. https://doi.org/10.1371/journal.pbio.0040277.

Dudash, M.R., Fenster, C.B., 2000. Inbreeding and outbreeding depression in fragmented populations. In: Young, A.G., Clarke, G.M. (Eds.), Eds.), Genetics, Demography and Viability of Fragmented Populations. Cambridge University Press, Cambridge, pp. 35-54. https://doi.org/10.1017/CBO9780511623448.005.

Edmands, S., Timmerman, C.C., 2003. Modeling factors affecting the severity of outbreeding depression. Conserv. Biol. 17, 883-892. https://doi.org/10.1046/j.15231739.2003.02026.x.

Fenster, C.B., Martén-Rodríguez, S., 2007. Reproductive assurance and the evolution of pollination specialization. Int. J. Plant Sci. 168, 215-228. https://doi.org/10.1086/ 509647.

Fenu, G., Cogoni, D., Bacchetta, G., 2016. The role of fencing in the success of threatened plant species translocation. Plant Ecol. 217, 207-217. https://doi.org/10.1007/ s11258-015-0517-1.

Fenu, G., Cogoni, D., Navarro, F.B., Concas, E., Bacchetta, G., 2017. The importance of the Cisto-Lavanduletalia coastal habitat on population persistence of the narrow endemic Dianthus morisianus (Caryophyllaceae). Plant Species Biol. 32, 156-168. https://doi. org/10.1111/1442-1984.12138.

Fenu, G., Cogoni, D., Ulian, T., Bacchetta, G., 2013. The impact of human trampling on a threatened coastal Mediterranean plant: the case of Anchusa littorea Moris (Boraginaceae). Flora Morphol. Distrib. Funct. Ecol. Plants 208, 104-110. https:// doi.org/10.1016/j.flora.2013.02.003.

Fenu, G., Bacchetta, G., Charalambos, S.C., Fournaraki, C., Giusso del Galdo, G.P., Gotsiou, P., Kyratzis, A., Piazza, C., Vicens, M., Pinna, M.S., Montmollin, Bde, 2019. An early evaluation of translocation actions for endangered plant species on Mediterranean islands. Plant Divers. 41, 94-104. https://doi.org/10.1016/j.pld. 2019.03.001.

Fernández, J.D., Bosch, J., Nieto-Ariza, B., Gómez, J.M., 2012. Pollen limitation in a narrow endemic plant: geographical variation and driving factors. Oecologia 170 , 421-431. https://doi.org/10.1007/s00442-012-2312-1.

Fisogni, A., Cristofolini, G., Rossi, M., Galloni, M., 2011. Pollinator directionality as a response to nectar gradient: promoting outcrossing while avoiding geitonogamy. Plant Biol. 13, 848-856. https://doi.org/10.1111/j.1438-8677.2011.00453.x.

Gargano, D., Fenu, G., Bernardo, L., 2017, plx031. Local shifts in floral biotic interactions in habitat edges and their effect on quantity and quality of plant offspring. AoB Plants 9. https://doi.org/10.1093/aobpla/plx031.

Gargano, D., Gullo, T., Bernardo, Li., 2009. Do inefficient selfing and inbreeding depression challenge the persistence of the rare Dianthus guliae Janka (Caryophyllaceae)? Influence of reproductive traits on a plant's proneness to extinction. Plant Species Biol. 24, 69-76. https://doi.org/10.1111/j.1442-1984.2009. 00239.x.

Godefroid, S., Piazza, C., Rossi, G., Buord, S., Stevens, A.-D., Aguraiuja, R., Cowell, C., Weekley, C.W., Vogg, G., Iriondo, J.M., Johnson, I., Dixon, B., Gordon, D., Magnanon, S., Valentin, B., Bjureke, K., Koopman, R., Vicens, M., Virevaire, M., Vanderborght, T., 2011. How successful are plant species reintroductions? Biol. Conserv. 144, 672-682. https://doi.org/10.1016/j.biocon.2010.10.003.

Gómez, J.M., Abdelaziz, M., Lorite, J., Jesús Muñoz-Pajares, A., Perfectti, F., 2010. Changes in pollinator fauna cause spatial variation in pollen limitation. J. Ecol. 98, 1243-1252. https://doi.org/10.1111/j.1365-2745.2010.01691.x.
Goodwillie, C., Kalisz, S., Eckert, C.G., 2005. The evolutionary enigmaof mixed mating: occurrence, theoretical explanations, and empirical evidence. Annu. Rev. Ecol. Evol. Syst. 36, 47-79. https://doi.org/10.1146/annurev.ecolsys.36.091704.175539.

Grindeland, J.M., Sletvold, N., Ims, R.A., 2005. Effects of floral display size and plant density on pollinator visitation rate in a natural population of Digitalis purpurea. Funct. Ecol. 19, 383-390. https://doi.org/10.1111/j.1365-2435.2005.00988.x.

Guerrant, E.O., 2013. The value and propriety of reintroduction as a conservation tool for rare plants. Botany 91 https://doi.org/10.1139/cjb-2012-0239. v-x.

Guo, H., Mazer, S.J., Du, G., 2010. Geographic variation in seed mass within and among nine species of Pedicularis (Orobanchaceae): effects of elevation, plant size and seed number per fruit. J. Ecol. 98, 1232-1242. https://doi.org/10.1111/j.1365-2745. 2010.01688.x.

Hothorn, T., Bretz, F., Westfall, P., 2008. Simultaneous inference in general parametric models. Biom. J. 50, 346-363. https://doi.org/10.1002/bimj.200810425.

Husband, B.C., Schemske, D.W., 1996. Evolution of the magnitude and timinf of inbreeding depression in plants. Evolution (N. Y). 50, 54-70. https://doi.org/10.1111/ j.1558-5646.1996.tb04472.x.

Kalisz, S., Vogler, D.W., 2003. Benefits of autonomous selfing under unpredictable pollinator environments. Ecology 84, 2928-2942. https://doi.org/10.1890/02-0519.

Keller, L.F., Waller, D.M., 2002. Inbreeding effects in wild populations. Trends Ecol. Evol. (Amst.) 17, 230-241. https://doi.org/10.1016/S0169-5347(02)02489-8.

Larrinaga, A.R., Fagúndez, J., Guitián, P., Guitián, J., Garrido, J.L., 2014. Effect of plant traits and population structure on the female reproductive success of the endemic Primula elatior subsp. Bergidensis (Primulaceae). Plant Biosyst. - An Int. J. Deal. with all Asp. Plant Biol. 148, 1040-1048. https://doi.org/10.1080/11263504.2014. 970241.

Larson, B.M.H., Barrett, S.C.H., 2000. A comparative analysis of pollen limitation in flowering plants. Biol. J. Linn. Soc. Lond. 69, 503-520. https://doi.org/10.1111/j. 1095-8312.2000.tb01221.x.

Lázaro, A., Traveset, A., 2006. Reproductive success of the endangered shrub Buxus balearica Lam. (Buxaceae): pollen limitation, and inbreeding and outbreeding depression. Plant Syst. Evol. 261, 117-128. https://doi.org/10.1007/s00606-005-0404-7.

Lloyd, D.G., Schoen, D.J., 1992. Self- and cross-fertilization in plants. i. Functional dimensions. Int. J. Plant Sci. 153, 358-369. https://doi.org/10.1086/297040.

Luijten, S.H., Kery, M., Oostermeijer, J.G.B., 2002. Demographic consequences of inbreeding and outbreeding in Arnica montana: a field experiment. J. Ecol. 90, 593-603. https://doi.org/10.1046/j.1365-2745.2002.00703.x.

Maschinski, J., Duquesnel, J., 2007. Successful reintroductions of the endangered longlived Sargent's cherry palm, Pseudophoenix sargentii, in the Florida keys. Biol. Conserv. 134, 122-129. https://doi.org/10.1016/j.biocon.2006.07.012.

Menges, E.S., Smith, S.A., Weekley, C.W., 2016. Adaptive introductions: how multiple experiments and comparisons to wild populations provide insights into requirements for long-term introduction success of an endangered shrub. Plant Divers. 38, 238-246. https://doi.org/10.1016/j.pld.2016.09.004.

Monks, L., Coates, D., Bell, T., Bowles, M.L., 2012. Determining Success criteria for reintroductions of threatened Long-lived plants. Plant Reintroduction in a Changing Climate. Island Press/Center for Resource Economics, Washington, DC, pp. 189-208. https://doi.org/10.5822/978-1-61091-183-2 11.

Nebot, A., Cogoni, D., Fenu, G., Bacchetta, G., 2018. Comparing the flowering phenology between the only natural and a translocated population of Dianthus morisianus. Bot. Lett. 165, 506-513. https://doi.org/10.1080/23818107.2018.1505546.

Nebot, A., Cogoni, D., Fenu, G., Bacchetta, G., 2016. Floral biology and breeding system of the narrow endemic Dianthus morisianus Vals. (Caryophyllaceae). Flora - Morphol. Distrib. Funct. Ecol. Plants 219, 1-7. https://doi.org/10.1016/j.flora.2015.12.004.

Ollerton, J., Lack, A., 1998. Relationships between flowering phenology, plant size and reproductive success in Lotus corniculatus (Fabaceae). Plant Ecol. 139, 35-47. https:// doi.org/10.1023/A:1009798320049.

Orsenigo, S., Montagnani, C., Fenu, G., Gargano, D., Peruzzi, L., Abeli, T., Alessandrini, A., Bacchetta, G., Bartolucci, F., Bovio, M., Brullo, C., Brullo, S., Carta, A., Castello, M., Cogoni, D., Conti, F., Domina, G., Foggi, B., Gennai, M., Gigante, D., Iberite, M., Lasen, C., Magrini, S., Perrino, E.V., Prosser, F., Santangelo, A., Selvaggi, A., Stinca, A., Vagge, I., Villani, M., Wagensommer, R.P., Wilhalm, T., Tartaglini, N., Duprè, E., Blasi, C., Rossi, G., 2018. Red Listing plants under full national responsibility: extinction risk and threats in the vascular flora endemic to Italy. Biol. Conserv. 224, 213-222. https://doi.org/10.1016/j.biocon.2018.05.030.

Pavlik, B.M., 1996. Defining and measuring success. In: Falk, D.A., Millar, C.I., Olwell, M. (Eds.), Restoring Diversity: Strategies for the Reintroduction of Endangered Plants. Island Press, Washington, DC, USA, pp. 127-155.

Picó, F.X., Van Groenendael, J., 2007. Large-scale plant conservation in European seminatural grasslands: a population genetic perspective. Divers. Distrib. 13, 920-926. https://doi.org/10.1111/j.1472-4642.2007.00349.x.

Schemske, D.W., Husband, B.C., Ruckelshaus, M.H., Goodwillie, C., Parker, I.M., Bishop, J.G., 1994. Evaluating approaches to the conservation of rare and endangered plants. Ecology 75, 584-606. https://doi.org/10.2307/1941718.

Tamura, S., Kudo, G., 2000. Wind pollination and insect pollination of two temperate willow species, Salix miyabeana and Salix sachalinensis. Plant Ecol. 147, 185-192. https://doi.org/10.1023/A:1009870521175.

Weisenberger, L.A., Weller, S.G., Sakai, A.K., 2014. Remnants of populations provide effective source material for reintroduction of an endangered Hawaiian plant, Schiedea kaalae (Caryophyllaceae). Am. J. Bot. 101, 1954-1962. https://doi.org/10. 3732/ajb.1400271. 